\title{
Anti-Nogo-A antibody promotes brain function recovery after cardiopulmonary resuscitation in rats by reducing apoptosis
}

\author{
QINQIN WU, HAIHONG ZHANG, HU NIE and ZHI ZENG
}

\author{
Emergency Department, West China Hospital, Sichuan University, Wuhou, Chengdu, Sichuan 610041, P.R. China
}

Received March 23, 2019; Accepted August 8, 2019

DOI: $10.3892 / \mathrm{mmr} .2019 .10825$

\begin{abstract}
Brain injury after cardiac arrest (CA) and cardiopulmonary resuscitation (CPR) is the main cause of neurological dysfunction and death in cardiac arrest. To assess the effect of Nogo-A antibody on brain function in rats following CPR and to explore the underlying mechanisms, CA/CPR (ventricular fibrillation) rats were divided into the CPR+Nogo-A, $\mathrm{CPR}+$ saline and sham groups. Hippocampal caspase-3 levels were detected by RT-PCR and immunoblotting. Next, Nogo-A, glucose regulated protein 78 (GRP78), C/EBP homologous protein (CHOP), cysteinyl aspartate specific proteinase-12 (casapse-12), Bcl-2 and Bax protein levels in the hippocampus were detected by immunoblotting. Coronal brain sections were analyzed by TUNEL assay to detect apoptosis at $72 \mathrm{~h}$, while Nissl staining and electron microscopy were performed to detect Nissl bodies and microstructure at $24 \mathrm{~h}$, respectively. Finally, rats were assessed for neurologic deficits at various times. Nissl staining revealed morphological improvement after Nogo-A antibody treatment. Sub-organelle structure was preserved as assessed by electron microscopy in model animals post-antibody treatment; neurological function was improved as well $(\mathrm{P}<0.05)$, while the apoptosis index was decreased $(26.2 \pm 9.85$ vs. $46.6 \pm 12.95 \%$; $\mathrm{P}<0.05)$. Hippocampal caspase-3 mRNA and protein, Nogo-A protein levels were significantly decreased after antibody treatment $(\mathrm{P}<0.05)$. Hippocampal Nogo-A expression was positively correlated with caspase-3 (Pearson's correlation; $\mathrm{r}=0.790, \mathrm{P}=0.000$ ). Hippocampal GRP78 and Bcl-2 protein levels were higher after antibody treatment than these levels noted in the model animals $(\mathrm{P}<0.05)$, while $\mathrm{CHOP}$, caspase-12 and Bax levels were reduced $(\mathrm{P}<0.05)$. Nogo-A antibody ameliorates neurological function after restoration of spontaneous circulation (ROSC),
\end{abstract}

Correspondence to: Dr Hu Nie or Dr Zhi Zeng, Emergency Department, West China Hospital, Sichuan University, 37 Guoxue Alley, Wuhou, Chengdu, Sichuan 610041, P.R. China

E-mail: 456nh@163.com

E-mail: zengzhi@cd120.com

Key words: cardiac arrest, Nogo-A, cardiopulmonary resuscitation, apoptosis, caspase-3 possibly by suppressing apoptosis induced by endoplasmic reticulum stress.

\section{Introduction}

Sudden cardiac arrest (CA) is a major public health challenge and the leading cause of death worldwide, imposing a heavy burden on patients and society (1). Only $17-49 \%$ of CA victims are able to regain self-circulation. Meanwhile, $80 \%$ of CA survivors present with a certain degree of coma, and very few fully recover brain function. Brain damage after continuous hypoxia remains the leading cause of death in CA (2). Postresuscitation syndrome is characterized by cerebral injury, cardiovascular injury, ischemia/reperfusion (I/R) injury and systemic inflammatory reaction after hypoxia (3), which may aggravate ischemic encephalopathy (4). Effective intervention for brain injury after CA has important clinical significance and social benefits. How to reduce brain function damage after CA has become a research 'hot' topic. Unfortunately, there is no specific pharmacological treatment for $\mathrm{I} / \mathrm{R}$ injury after restoration of spontaneous circulation (ROSC) $(3,4)$.

Nogo-A is widely found in neurons of the central nervous system (CNS) and oligodendrocytes, and is considered an inhibitor of neurite outgrowth and axon regeneration after CNS injury. Nogo-A expression increases after focal cerebral ischemia reperfusion injury (5) and stroke (6). Increased Nogo-A can affect the plasticity of the CNS and prevent the improvement of neural function. Anti-Nogo-A treatment promotes axonal sprouting and neuro-structural plasticity to recover neural function after ischemic stroke and injury (7). Nogo-A plays an important role in nerve regeneration in the CNS; therefore, regulating Nogo-A is of great significance for nerve function recovery (5). These results were derived from a study of focal cerebral ischemia, but there are few reports assessing total cerebral ischemia, especially Nogo-A expression in the CA/CPR (cardiac arrest/cardiopulmonary resuscitation) model. Meanwhile, there is no report concerning the effect of Nogo-A antibody on brain function after intracerebroventricular injection in rats after CA/CPR. Studies found that anti-Nogo-A treatment affects neurogenesis after stoke. Research assessing Nogo-A focuses on regeneration inhibition in the chronic period (8), and few studies have evaluated Nogo-A changes in the CA/CPR model in the acute phase. In recent years, studies evaluating Nogo-A have shown that intervention with myocardial Nogo-A could reduce 
apoptosis in cardiomyocytes (9). We speculated that Nogo-A may be associated with apoptosis in the brain. Ephedrine with or without hyperbaric oxygen inhibits caspase-3 and Nogo-A expression, and reduces the degree of brain damage caused by ischemia (10) in the neonatal brain injury model. We speculated that Nogo-A may be associated with apoptosis after CA/CPR. Nogo-A contains double lysine motifs and is mainly found in the endoplasmic reticulum (ER), where it aids in the formation of ER tubules (11) and maintenance of normal ER shape (12). Based on the above facts, we hypothesized that Nogo-A may be associated with ER stress-related apoptosis in neuron cells during global brain I/R injury in the CA/CPR model. It is well-known that $\mathrm{C} / \mathrm{EBP}$ homologous protein (CHOP) and glucose regulated protein 78 (GRP78) are ER stress markers, and cysteinyl aspartate specific proteinase-12 (casapse-12) is a specific marker of ER stress-related apoptosis (13). To investigate the effect of Nogo-A antibody on brain tissue structure and function in rats with CA/CPR and to explore the possible mechanism, providing an experimental basis for brain protection in the CNS, the effects of Nogo-A antibody on neuron cell morphology and caspase-3, Nogo-A, GPR78, CHOP, caspase-12, Bcl-2 and Bax expression levels were assessed in the CA/CPR rat model at different timepoints after ROSC.

\section{Materials and methods}

Animal preparation. A total of 115 Wistar rats (male, age 3-months old, weight 300-400 g) were purchased from the Sichuan University Laboratory Animal Center. They were housed in standard rodent housing with soft wood bedding, maintained at room temperature $\left(23 \pm 2^{\circ} \mathrm{C}\right.$, humidity $\left.50 \pm 5 \%\right)$, on a 12:12-h light:dark cycle with ad libitum access to water and food. The West China Hospital's Experimental Animal Ethics Committee approved the study protocol. Rats were anesthetized by intraperitoneal injection of $45 \mathrm{mg} / \mathrm{kg} 1.5 \%$ sodium pentobarbital. Animal tracheas were intubated (14G artery puncture needle cannula; BD Bioscience) and mechanically ventilated (HX-100E Ventilator, Chengdu Taimeng Technology Co., Ltd.; 60 breaths per min). A 22G artery puncture needle cannula was inserted into the right femoral artery and vein. A pressure transducer (PT-100 blood pressure transducer; Chengdu Taimeng Technology Co. Ltd.) was used to monitor arterial blood pressure online. All catheters were blushed intermittently with saline containing $2.5 \mathrm{IU} / \mathrm{ml}$ crystalline bovine heparin. Subcutaneous needle electrodes were used to monitor electrocardiographic recordings continuously. Data were recorded using a BL-420F biological signal acquisition and procession system (BL-420F; Chengdu Taimeng Technology Co. Ltd.).

Modeling cardiac arrest. Experimental procedures in the rat studies were executed based on Utstein-Style Guideline for Uniform Reporting of Laboratory CPR Research (14). A 5F pacing catheter with ring electrodes (Medtronic, Inc.) was placed in the esophagus for transesophageal induction of ventricular fibrillation (15). The distance between the electrode and incisor was $7 \mathrm{~cm}$. A heating plate and light were used to maintain the temperature between 36.5 and $37.5^{\circ} \mathrm{C}$. The ECG and hemodynamic data were monitored for $15 \mathrm{~min}$.
Ventricular fibrillation was induced using $20 \mathrm{~V} / 30 \mathrm{~Hz}$ with a $10 \mathrm{msec}$ wave width alternating current via an esophageal electrode (Medtronic Inc.). CA criteria: i) ECG showed ventricular fibrillation, pulseless electricity activity, or asystole. ii) mean arterial pressure (MAP) below $25 \mathrm{mmHg}$. Artificial ventilation was stopped when inducing CA. After 5 min of CA, CPR was started by artificial ventilation $(80$ breaths $/ \mathrm{min}$, tidal volume of $6 \mathrm{ml} / \mathrm{kg}$, with pure oxygen) and thoracic compression with 2 fingers over the sternum at a rate of 200 compressions/min paced by a metronome with the depth of $1 / 3$ of anteroposterior diameter of chest and adjusting according to maintain aortic diastolic pressure over $20 \mathrm{mmHg}$. Advanced cardiac life support, including epinephrine (Shanghai Hefeng Pharmaceutical Co., Ltd.; $20 \mu \mathrm{g} / \mathrm{kg}$ body weight, i.v.) administration, external defibrillation (5J, HeartSmart XL defibrillator; Philips Medical Systems B.V.), was initiated. If first defibrillation did not result in ROSC, CPR was sustained and defibrillation was attempted every $2 \mathrm{~min}$. Resuscitation procedures were sustained until restoration of spontaneous circulation (ROSC). ROSC criteria: i) ECG showed supraventricular rhythm (sinus, atrial, borderline rhythm); ii) mean arterial pressure (MAP) over $60 \mathrm{mmHg}$ maintained for more than $10 \mathrm{~min}$. If ROSC did not occur within $10 \mathrm{~min}$ of CPR, resuscitation was terminated (Fig. 1).

Intracerebroventricular administration of Nogo-A antibody. The rats were randomized into three groups after ROSC. The Treatment group received Nogo-A antibody $(n=50)$ while the Model group $(n=50)$ received saline. In addition, the Sham-operated rats without CA served as non-ischemic controls $(n=15)$. Ten minutes after ROSC, rats were placed into a stereotaxic apparatus (RWD Desktop digital brain stereotaxic instrument 68025; Shenzhen Reward Life Technology Co. Ltd.). A stainless cannula was inserted into the right lateral ventricle (bregma coordinates: $1.5 \mathrm{~mm}$ lateral and $0.8 \mathrm{~mm}$ posterior to the bregma, at a depth of $3.5 \mathrm{~mm}$ ) (16) and connected to an osmotic minipump (Microsyringe pump ALC_IP 600Gb; Shanghai Alcott Biotechnology Co., Ltd.). Continuous intracerebroventricular application of Nogo-A antibody (17) $(200 \mu \mathrm{g} / \mathrm{ml}, 1.0 \mu \mathrm{l} / \mathrm{min}$ pump rate, $20 \mu \mathrm{l})$ or placebo saline $(1.0 \mu \mathrm{l} / \mathrm{min}$ pump rate, $20 \mu \mathrm{l})$ was carried out for 20 min (18). After 1, 2, 4, 6, 24, 48 and $72 \mathrm{~h}$, respectively, rats were anesthetized and decapitated. The brains were removed and cryo-fixed overnight before embedding and sectioning. At the hippocampal level (approximately at the bregma $-3.5 \mathrm{~mm}$ ), coronal brain sections $(10-\mu \mathrm{m})$ were cut and placed on glass slides. Then, hippocampal samples were collected for western blot and RT-PCR analysis.

Assessment of neurological deficit score (NDS). NDSs were measured to evaluate the neurologic state in the Sham, Model and Treatment groups at 1, 2 and 3 days, respectively, after CA/CPR as described previously (19). NDS assessment included seven variables such as general behavior, brainstem function, exercise assessment, sensory function, motor behavior, behaviors and convulsions. An NDS of 80 was assigned to reflect normal brain function, whereas an NDS of 0 indicated brain death. All assessments were examined and confirmed by two separate investigators blinded to the treatment (20). 


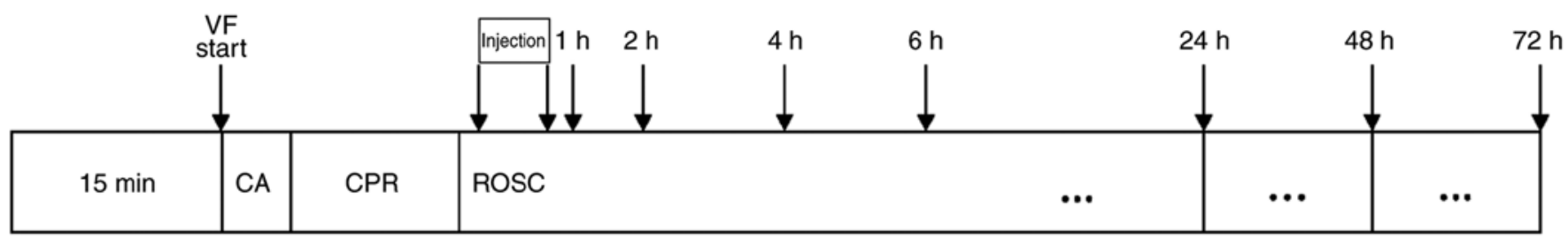

Figure 1. Experimental procedure. CA, cardiac arrest; VF, ventricular fibrillation; CPR, cardiopulmonary resuscitation; ROSC, restoration of spontaneous circulation.

Reverse transcription-quantitative $(R T-q) P C R$. Total RNA was obtained from dissected hippocampal samples using TRIzol reagent as directed by the manufacturer (Invitrogen; Thermo Fisher Scientific, Inc.). First-strand cDNA was synthesized with Revert Aid ${ }^{\mathrm{TM}}$ First Strand cDNA Synthesis Kit from Fermentas (Thermo Fisher Scientific, Inc.). Amplification was performed on an FTC2000 real-time fluorescent quantitative gene amplification instrument (Funglyn). Each reaction contained $1 \mu \mathrm{l}$ of TaqMan probe, $15.34 \mu \mathrm{l}$ of PCR water, $5 \mu \mathrm{l}$ of cDNA and $1 \mu \mathrm{l}$ of each primer (final concentration $10 \mu \mathrm{M})$. Thermal cycling included an amplification cycle of denaturation at $94^{\circ} \mathrm{C}$ for $2 \mathrm{~min}$, followed by 40 cycles of $94^{\circ} \mathrm{C}$ for $20 \mathrm{sec}$ and $54^{\circ} \mathrm{C}$ for $20 \mathrm{sec}\left(\beta\right.$-actin) and $52^{\circ} \mathrm{C}$ for $20 \mathrm{sec}$ (caspase-3) (21). Primers included: $\beta$-actin (111 bp), forward 5'-GAAGATCAAGATCATTGCTCCT-3' and reverse 5'-TAC TCCTGCTTGCTGATCCACA-3'; caspase-3 (156 bp), forward 5'-CCGAAACTCTTCATCATTCA-3' and reverse 5'-CCA GGAATAGTAACCGGGT-3'.

Relative mRNA expression was assessed by the comparative $C_{q}\left(2^{-\Delta \Delta C q}\right)$ method $(22,23)$. Transcript levels of caspase-3 were determined by RT-PCR and normalized to $\beta$-actin as an endogenous control.

Western blot analysis. Hippocampal tissue samples were homogenized in ice-cold suspension buffer (Bioteke Corp.), and centrifuged $\left(20 \mathrm{~min}, 4^{\circ} \mathrm{C}, 12000 \mathrm{x} \mathrm{g}\right)$, and supernatants were transferred into a $20-\mu 1$ tube. After protein quantitation using the BCA protein concentration kit (Beyotime Biotechnology), protein extracts (30 $\mu \mathrm{g}$ each) were separated by $10 \%$ SDS-PAGE (sodium dodecyl sulfate-polyacrylamide gel electrophoresis) and transferred onto polyvinylidene fluoride (PVDF) membranes (Millipore Corp.). The membranes were then blocked with 5\% non-fat dried milk in PBS. After electroblotting, the membranes were incubated overnight with anti-Nogo-A (cat. no. SC25660; dilution 1:500; Santa Cruz Biotechnology, Inc.), anti-caspase-3 (cat. no. 9662S; dilution 1:1,000; Cell Signaling Technology, Inc.), anti- $\beta$-actin (cat. no. bsm-33036M; dilution 1:1,000; BIOSS), anti-GRP78 BiP (cat. no. ab108613; dilution 1:1,000 Abcam), anti-DDIT3 (cat. no. ab179823; dilution 1:1,000; Abcam), anti-caspase-12 (cat. no. ab62484; dilution 1:1,000; Abcam), anti-Bcl-2 (cat. no. ab59348; dilution 1:1,000; Abcam) and anti-Bax (cat. no. ab32503; dilution 1:1,000; Abcam) primary antibodies, respectively, followed by a 1-h incubation with horseradish peroxidase-conjugated goat-anti-rabbit antibody (dilution 1:1,000; ZB-2301; OriGene Technologies, Inc.). The film was photographed and scanned, and Quantity One Analysis Software 4.6 (Bio-Rad Laboratories, Inc.) was used for quantifying protein gray values. Relative expression of the target protein was assessed as its gray-scale value divided by that of the internal control $\beta$-actin.

Nissl staining. The animals were anesthetized by $1.5 \%$ sodium pentobarbital and sacrificed at various time-points. Rats were transcardially perfused with $250 \mathrm{ml}$ saline at $4^{\circ} \mathrm{C}$ (24). Brains were removed and fixed for one week at $4^{\circ} \mathrm{C}$. A series of 70 , 80,90 and $95 \%$ alcohol solutions and xylene were used to dehydrate the brain samples. The prepared paraffin-embedded blocks were cut coronally and mounted onto slides. Five fields in each slide were randomly assessed under an Olympus BX41 optical microscope (Olympus Corporation) with a magnification of $x 400$, photographed by an attached camera (Olympus DP71, Olympus Corporation) and quantified with Image Pro Plus software version 6.0 (Media Cybernetics, Inc.). Average optical density (AOD) values were analyzed according to a previous report (25).

Electron microscopy. Rats were deeply anesthetized with $1.5 \%$ sodium pentobarbital and transcardially perfused with $200 \mathrm{ml}$ $4 \%$ paraformaldehyde at $4^{\circ} \mathrm{C}$. The brain tissue was quickly removed, placed on ice, cut at $0.5 \times 0.5 \times 0.5 \mathrm{~cm}$ with a sharp blade, and placed in a pre-cooled $2.5 \%$ glutaraldehyde solution for at least $2 \mathrm{~h}$ at $4^{\circ} \mathrm{C}$. The, the tissues were rinsed 3 times with a $0.2 \mathrm{M}$ phosphate buffer saline solution $(\mathrm{pH}=7.4)$ for $15 \mathrm{~min}$. Next, they were placed in $1 \%$ osmium solution for at least $1 \mathrm{~h}$ and rinsed again as described previously (16). The samples were soaked in gradient ethanol series for $15 \mathrm{~min}$, respectively, for dehydration. The samples were embedded in epoxy resin, and 70-nm-thick sections were prepared. The slices were stained with saturated acetate $30 \mathrm{~min}$ and treated with lead for 5-8 min (24). After staining, slices were rinsed with distilled water and assessed under a transmission electron microscope (Hitachi H-7500 transmission electron microscopy; Hitachi Corp., Japan). The changes in neurons, mitochondria and ER were observed.

Terminal deoxynucleotidyl transferase (TdT)-mediated dUTP nick-end labelling (TUNEL) assay. Histological analysis by TUNEL assay is characterized by the incorporation of deoxyuridine triphosphate fluorescein-12 (12-d-UTP) at the DNA 30-OH ends, whose signal is amplified by the reaction involving the enzyme terminal deoxynucleotidyl transferase (rTdT); the fragmented DNA labeled with 12-dUTP fluorescein becomes visible under a fluorescence microscope. TUNEL staining was applied at $72 \mathrm{~h}$ after ROSC for the detection of neuronal apoptosis. For in situ staining of DNA fragmentation and apoptotic bodies, the TUNEL assay was used as described previously (21). An in situ cell death detection kit, the 
DeadEnd $^{\text {TM }}$ Fluorometric TUNEL system (Promega, USA), was used for coronal sections mounted on $12-\mu$ m slides $(n=3$ per group). The slides were washed with $0.05 \mathrm{M} \mathrm{PBS}$ and incubated for $2 \mathrm{~min}$ in $1 \%$ sodium citrate solution in $0.05 \mathrm{M}$ PBS at $4^{\circ} \mathrm{C}$. After additional washes in $0.1 \mathrm{M}$ PBS, $50 \mu \mathrm{l}$ of TUNEL reaction mixture was pipetted onto each slide. The slides were incubated for $60 \mathrm{~min}$ at $37^{\circ} \mathrm{C}$ in the dark and washed again with $0 . \mathrm{M}$ PBS three times. Then, slides were incubated in DAPI solution $(1: 65,000)$ for $5 \mathrm{~min}$ in the dark, washed with $0.1 \mathrm{M}$ PBS three times, allowed to dry and mounted with glycerol (26). The images were acquired under a DM4000B-M fluorescence microscope (magnification, $\mathrm{x} 400$ ) equipped with a color digital camera and diagnostic instruments (Leica Co., Germany). Image analysis adopted the double-blind method. Five film sections were randomly selected from each group of rats for analysis. TUNEL fluorescent signals located in the nucleus appeared as bright green dots, representing apoptotic cells; DAPI was used for nuclear staining. Apoptosis index $(\mathrm{AI})=$ green-stained cells/blue-stained cells.

Statistical analysis. The IBM-SPSS19 statistical software (SPSS Inc., Chicago, IL, USA) was used for statistical analysis. All western blot and PCR data are represented as relative expression based on the sham group. Continuous variables with normal distribution were presented as mean \pm standard deviation (mean \pm SD). Multiple group comparisons were performed by one way analysis of variance (ANOVA), with the least-significant difference (LSD) test for group pair comparisons. Pearson correlation analysis was used to examine the association of Nogo-A with caspase-3 in the hippocampus. $\mathrm{P}<0.05$ was considered as indicative of statistical significance.

\section{Results}

Rats after ROSC were randomized to a Model group and a Treatment group with $\mathrm{n}=6$ for $1,2,4,6,48$ and $72 \mathrm{~h}$ time-points and $\mathrm{n}=9$ for $24 \mathrm{~h}$ time-point. Five rats were dead within $72 \mathrm{~h}$ in each group. There were no significant differences in weights, heart rates, mean arterial pressures among groups at baseline. There were no significant differences in the number of defibrillations required and CPR duration between the Model and Treatment group. The survival rates at $72 \mathrm{~h}$ after ROSC in the Model group was 6 of 7 rats $(85.7 \%)$; the survival rates in the Treatment group was 6 of 7 rats $(85.7 \%)$. The survival rates in the Sham group was 6 of 6 rats $(100 \%)$.

Nissl staining. The cells in the Sham operation group (Fig. 2A) under light microscope were large, with Nissl bodies clearly visible. Reduced amounts of cells were observed in the Model group (Fig. 2B) compared with the Sham group. In the Treatment group (Fig. 2C), there were more cells in an arranged order; some Nissl bodies were clearly visible.

Average optical density (AOD) values in the Model and Treatment groups were significantly decreased compared with that of the Sham group. Meanwhile, AOD in the Treatment group was significantly higher than that of the Model group (Fig. 2D). There were significant differences in AOD among the three groups $(\mathrm{P}<0.001)$. These results indicated that Nogo-A antibody could preserve the Nissl bodies.
Ultrastructure of the brain samples. As shown in Fig. 3A, neuronal structure was clearly visible in the Sham group, with abundant cytoplasm; the rough ER was large and linear. The mitochondria were elliptical, rich and complete; the mitochondrial membrane was smooth, with visible double-layer structure. The mitochondrial ridge was clear and orderly. Ribosomes and glycogen granules were abundant. The nuclear membrane was clear and the chromatin dispersed uniformly in the nucleus. As shown in Fig. 3B, the rough ER was expanded obviously in the Model group; the mitochondria were swollen, and the mitochondrial crest decreased and disappeared. There was cell edema and vacuolar degeneration. Perinuclear plasmids, ribosomes and glycogen granules were sparse. As shown in Fig. 3C, ER expansion was less pronounced in the Treatment group than that in the Model group. The mitochondrial structure was well preserved, and the mitochondria were mildly swollen. The membrane was slightly fuzzy. The mitochondrial ridge was partially visible, and cavitation was reduced. Sub-organelle structure was preserved as assessed by electron microscopy in the Treatment group.

Apoptosis quantitated by TUNEL staining. Only a few cells in the Sham group underwent apoptosis, with an apoptotic index of $3 \pm 1.58 \%$; apoptotic index values were $46.6 \pm 12.95$ and $26.2 \pm 9.85 \%$ in the CPR Model and Treatment groups at $72 \mathrm{~h}$, respectively. Differences among the three groups were statistically significant $(\mathrm{F}=26.686, \mathrm{P}<0.001)$. The apoptosis index of the Treatment group was significantly lower than that of the Model group $(\mathrm{P}<0.05)$ (Fig. 4). These results revealed that the Nogo-A antibody overtly reduced the number of TUNEL-positive cells.

Changes in neurological function. In the Sham group, the neurological deficit scores (NDSs) showed no significant differences at the three time-points $(\mathrm{F}=0.830, \mathrm{P}=0.447)$. NDSs in both the Model and Treatment groups increased with time. Indeed, NDSs varied at different time-points in the Model $(\mathrm{F}=31.249, \mathrm{P}<0.001)$ and Treatment $(\mathrm{F}=33.924, \mathrm{P}<0.001)$ groups. The difference between the 48 and $72 \mathrm{~h}$ time-points was not significant in the Treatment group $(\mathrm{P}=0.055)$. NDSs in the Treatment and Model groups were lower than those of the Sham group, and differences were statistically significant $(\mathrm{P}<0.05)$. NDSs at all time-points in the Treatment group were higher than those of the Model group, and differences were statistically significant $(\mathrm{P}<0.05)$ (Fig. 5). These findings demonstrated that Nogo-A antibody could improve neurological function in rats after ROSC.

Caspase-3 mRNA levels in the cerebral hippocampus. Hippocampal caspase-3 mRNA levels in the Model group were increased after CPR and decreased at $4 \mathrm{~h}$, and then increased at $6 \mathrm{~h}$. The Treatment group showed decreased levels until $4 \mathrm{~h}$, followed by an increase. Hippocampal caspase- 3 mRNA amounts in the treatment group were lower than those of the Model group, and the difference was statistically significant $(\mathrm{P}<0.05)$. Hippocampal caspase-3 mRNA amounts in the Treatment group and in the Model group were higher than those of the Sham group, and the difference was statistically significant $(\mathrm{P}<0.05$; Fig. 6). Nogo-A antibody injection reduced caspase-3 mRNA expression $(\mathrm{P}<0.05)$. 

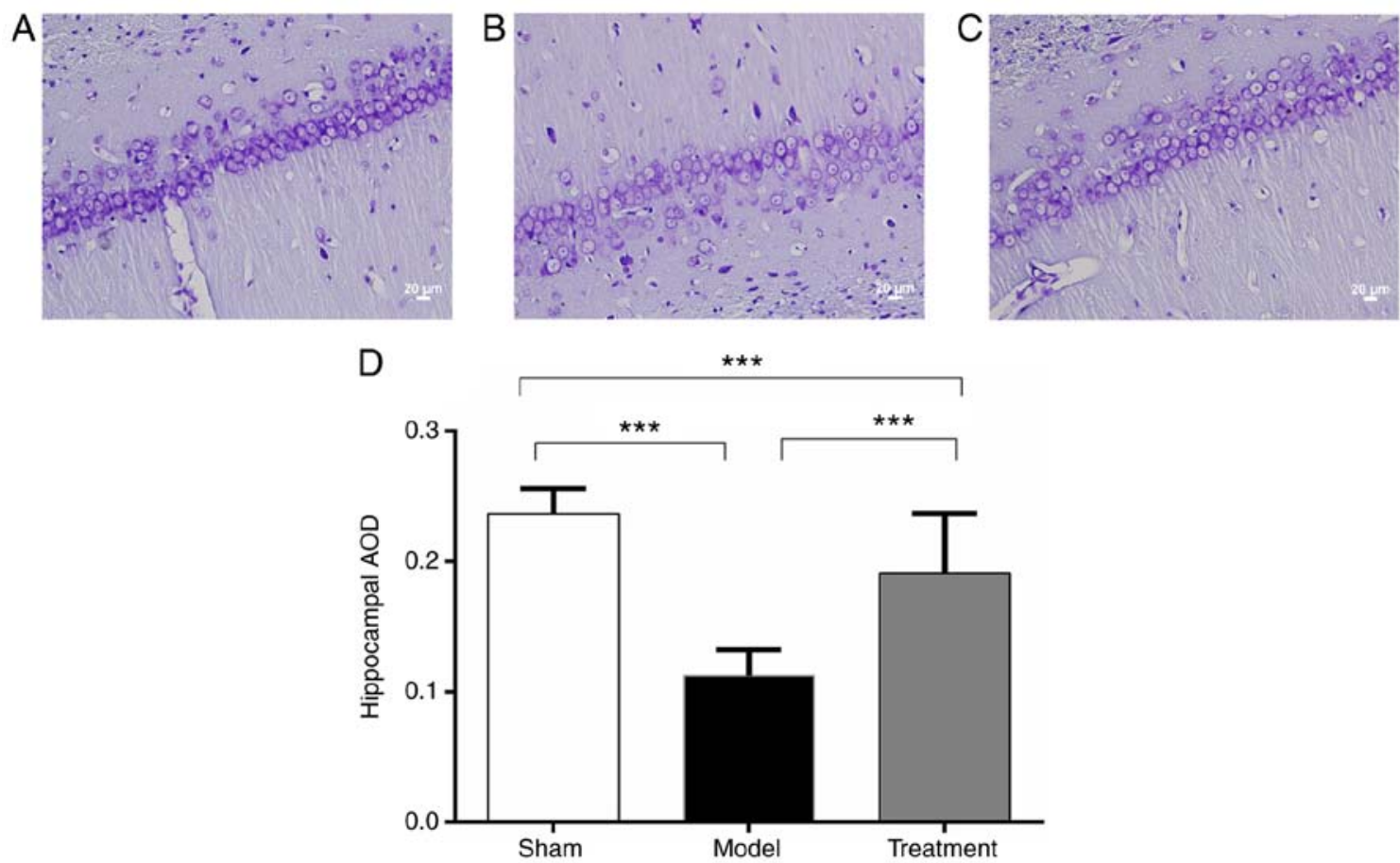

Figure 2. Nissl staining of neuronal cells in the hippocampus. (A) The Sham operation group; (B) the Model group; (C) the Treatment group (Nissl staining; magnification, $x 400)$. (D) Quantitative analysis ( $n=3$ ) revealed that the AOD was significantly higher in the treatment groups than that in the model group. Data are presented as mean $\pm \mathrm{SD}$. ${ }^{* * *} \mathrm{P}<0.001$, one way ANOVA followed by LSD test. AOD, average optical density. Groups: Treatment, received Nogo-A antibody $(\mathrm{n}=50)$; Model, received saline $(\mathrm{n}=50)$; Sham, Sham-operated rats without cardiac arrest (CA) serving as non-ischemic controls $(\mathrm{n}=15)$.
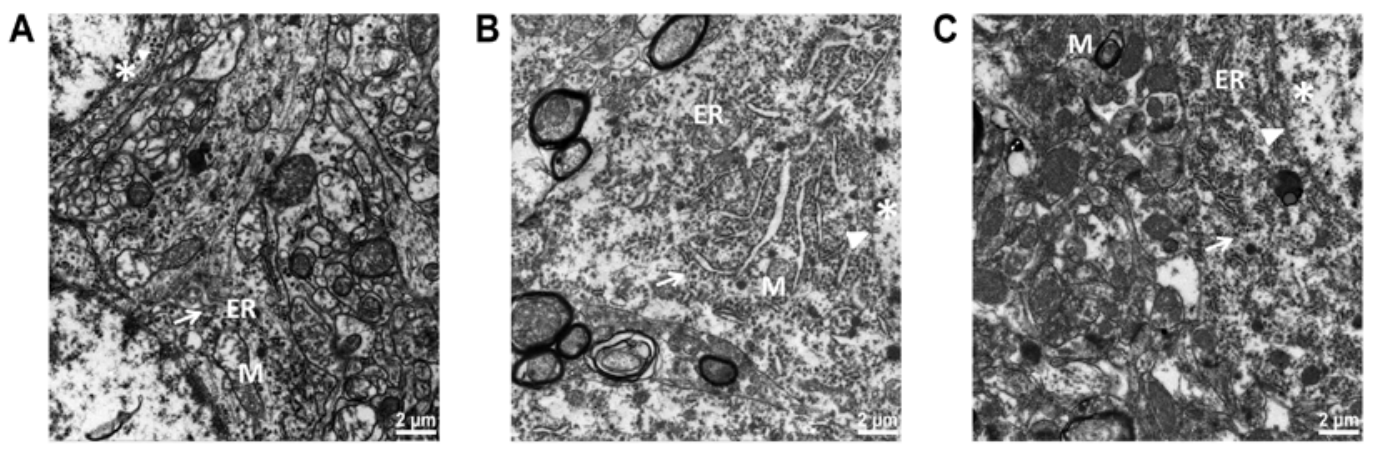

Figure 3. The hippocampal endoplasmic reticulum (ER) and mitochondrial ultrastructure examined by transmission electron microscope (TEM) (magnification, x30,000) (n=3). (A) the membranes of normal ER were continuous and integrated. Many ribosomes attached to the ER. (B) In the Model group, the structure of the ER was irregular, faulted and expanded irregularly. (C) In the Treatment group, the ER had a more complete structure. M, mitochondria; ER, endoplasmic reticulum. Arrows indicate ribosomes; arrowheads indicate nuclear membrane; asterisk indicates chromatin. Groups: Treatment, received Nogo-A antibody ( $\mathrm{n}=50)$; Model, received saline $(\mathrm{n}=50)$; Sham, Sham-operated rats without cardiac arrest (CA) serving as non-ischemic controls ( $\mathrm{n}=15)$.

Nogo-A and caspase-3 protein levels in the hippocampus. In the Model group, hippocampal Nogo-A protein levels increased gradually reaching a peak at $24 \mathrm{~h}$, and then decreased. The Treatment group showed decreased amounts at $4 \mathrm{~h}$, followed by an increase. Hippocampal Nogo-A protein amounts in the Model group were higher than those of the Sham group at all time-points $(\mathrm{P}<0.05)$, and hippocampal Nogo-A protein amounts in the Treatment group were lower than those of the Model group within $24 \mathrm{~h}(\mathrm{P}<0.05)$, and the decrease was most obvious at $4 \mathrm{~h}$ (Fig. 7A-C). Hippocampal caspase-3 protein levels in the Model group increased over time. In the Treatment group, hippocampal caspase- 3 protein increased over time as well. But hippocampal caspase-3 protein levels in the Treatment group were significantly lower than those of the Model group $(\mathrm{P}<0.05)$, but higher than those of the Sham group ( $\mathrm{P}<0.05)$. (Fig. 7A, B and $\mathrm{D})$.

Pearson's correlation showed that Nogo-A protein in the hippocampus was significantly positively correlated with caspase- $3(r=0.790, \mathrm{P}<0.001)$. These findings indicated that Nogo-A antibody injection could reduce Nogo-A and caspase- 3 protein amounts $(\mathrm{P}<0.05)$.

GRP78, CHOP, caspase-12, Bcl-and Bax protein levels in the hippocampus. The expression of GRP78 gradually increased in the hippocampus and decreased after peaking at $2 \mathrm{~h}$ in the Model group. However, GRP78 expression gradually increased and peaked at $4 \mathrm{~h}$, then increased again at $24 \mathrm{~h}$ in the Treatment group. GRP78 protein levels were higher in 

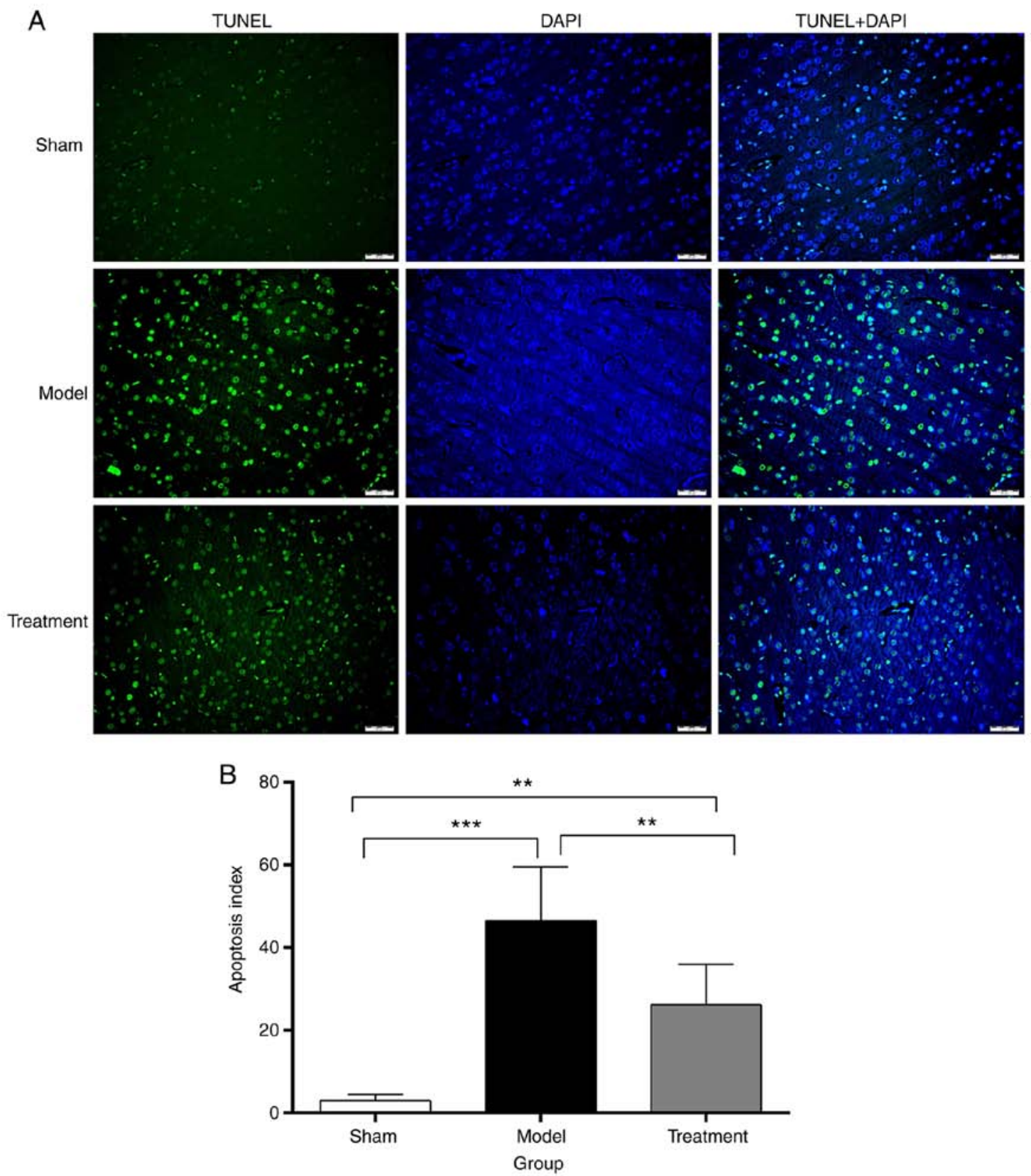

Figure 4. Nogo-A antibody reduces the number of TUNEL-positive cells. (A) DNA fragmentation was evaluated by TUNEL staining. (B) Quantitative comparison ( $\mathrm{n}=3$ ) of the apoptosis index among the Sham (white), Model (black) and Treatment group (gray). Data are presented as mean $\pm \mathrm{SD}$. ${ }^{* * *} \mathrm{P}<0.01$ and ${ }^{* * * *} \mathrm{P}<0.001$, one way ANOVA followed by LSD test. Groups: Treatment, received Nogo-A antibody ( $\mathrm{n}=50$ ); Model, received saline ( $\mathrm{n}=50$ ); Sham, Sham-operated rats without cardiac arrest (CA) serving as non-ischemic controls $(n=15)$.

the Treatment group compared with the Model group at 4, 6 and $24 \mathrm{~h}(\mathrm{P}<0.01)$. Hippocampal GRP78 protein levels in the Treatment and Model group were higher than those of the Sham group $(\mathrm{P}<0.05)$ (Fig. 8A).

CHOP protein expression varied significantly at different time-points. CHOP protein amounts in the Model group increased with time and peaked at $6 \mathrm{~h}$. The Treatment group had a similar profile. CHOP protein levels were lower in the Treatment group than levels in the Model group at 2, 4, 6 and $24 \mathrm{~h}(\mathrm{P}<0.01)$. Hippocampal CHOP protein levels in the Model group were higher than those of the Sham group $(\mathrm{P}<0.05)$. Hippocampal CHOP protein levels in the Model group were higher compared with the Sham group at 4,6 and $24 \mathrm{~h}(\mathrm{P}<0.05)($ Fig. 8B).
Caspase-12 expression increased at $2 \mathrm{~h}$, and peaked at $24 \mathrm{~h}$ in the Model group. Hippocampal caspase-12 levels in the Treatment group showed a trend of decrease with time, and no significant peak was observed. Caspase-12 protein levels were lower in the Treatment group compared with the Model group at 2, 6 and $24 \mathrm{~h}(\mathrm{P}<0.05)$. Hippocampal caspase-12 protein levels in the Model group were significantly higher than those of the Sham group at 4, 6 and $24 \mathrm{~h}(\mathrm{P}<0.05)$. Hippocampal caspase-12 protein levels in the Treatment group were lower than those of the Sham group at 2, 6 and $24 \mathrm{~h}(\mathrm{P}<0.05)$ (Fig. 8C).

Bcl-2 protein levels were decreased at $2 \mathrm{~h}$, and increased to a peak at $6 \mathrm{~h}$, then decreased in the Model group. Bcl-2 protein amounts in the Treatment group peaked at $2 \mathrm{~h}$ and 


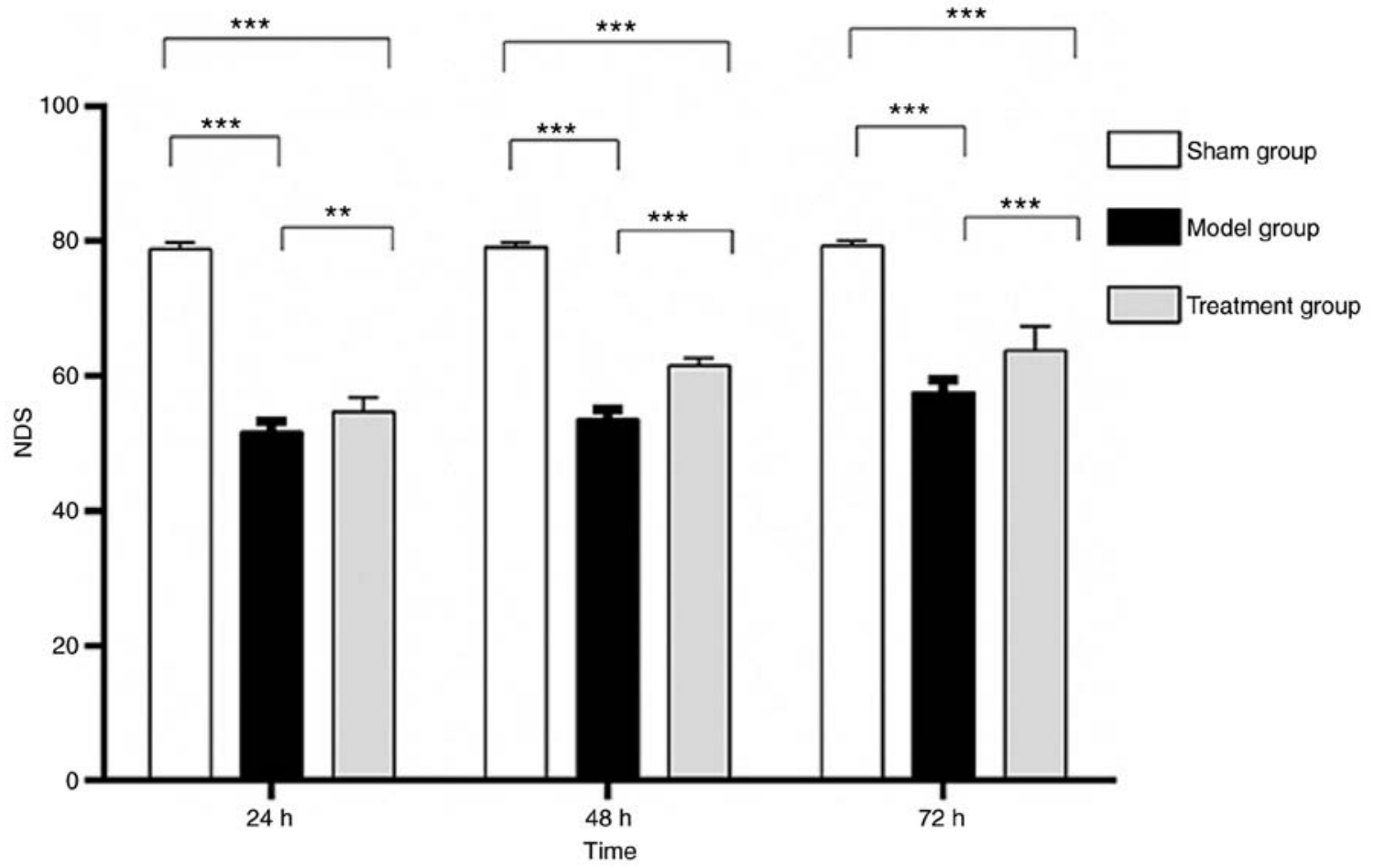

Figure 5. Nogo-A antibody improved the neurological function of the rats after $\mathrm{CA} / \mathrm{CPR}(\mathrm{n}=6)$. The graph shows mean $\pm \mathrm{SD}$ values at each time point. Sham group (white), Model group (black), Treatment group (gray). Data are presented as mean $\pm \mathrm{SD}$. ${ }^{* *} \mathrm{P}<0.01$ and ${ }^{* * *} \mathrm{P}<0.001$, one way ANOVA followed by LSD test. Groups: Treatment, received Nogo-A antibody $(\mathrm{n}=50)$; Model, received saline $(\mathrm{n}=50)$; Sham, Sham-operated rats without cardiac arrest (CA) serving as non-ischemic controls ( $\mathrm{n}=15)$. NDS, neurological deficit score; CA, cardiac arrest; CPR, cardiopulmonary resuscitation.

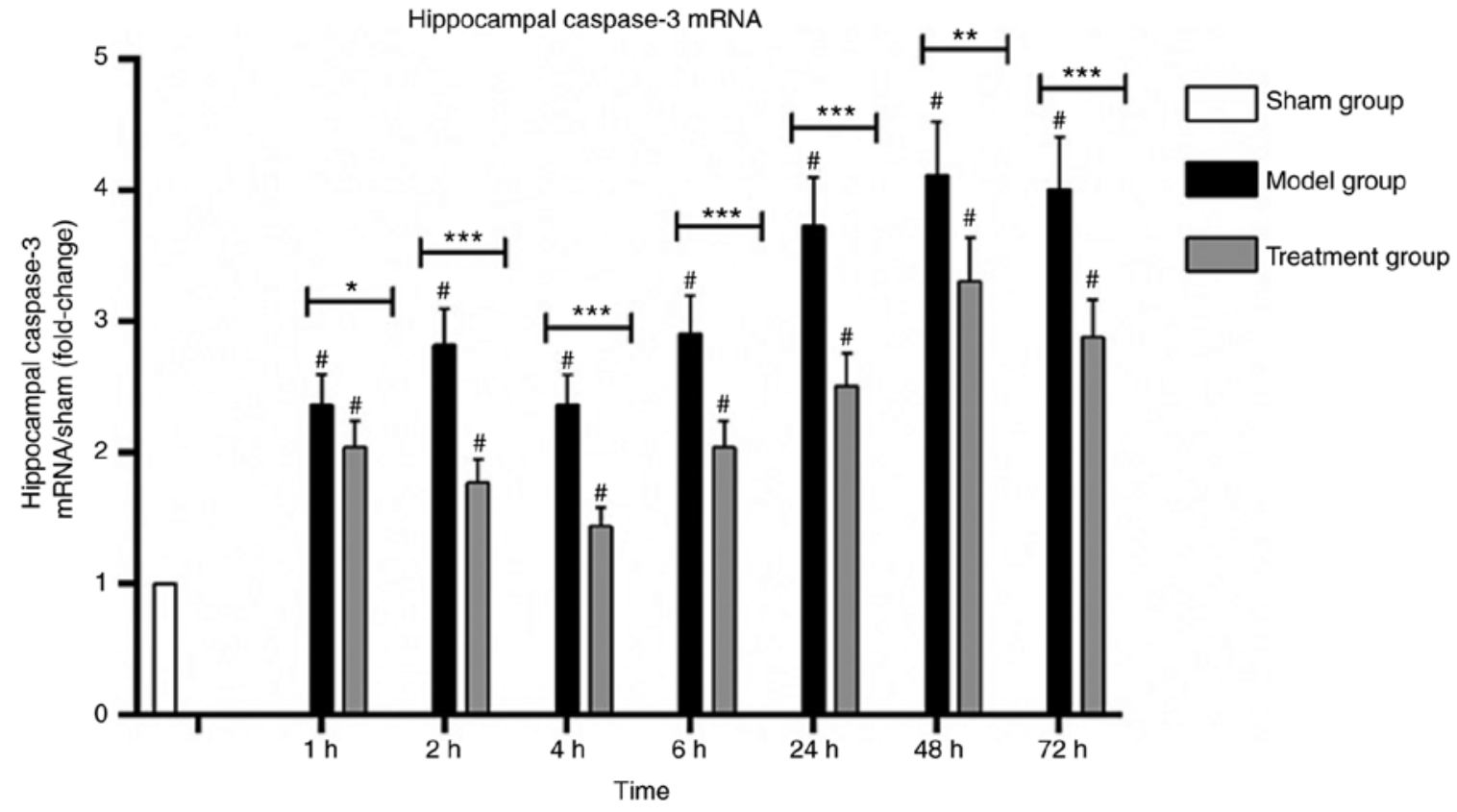

Figure 6. Expression of caspase-3 mRNA in the cerebral hippocampus ( $\mathrm{n}=3$ ). Graph shows mean \pm SD values at each time point. Sham group (white), Model group (black), Treatment group (gray). ${ }^{*} \mathrm{P}<0.05,{ }^{* *} \mathrm{P}<0.01$ and ${ }^{* * *} \mathrm{P}<0.001$, comparison between Model and Treatment group; ${ }^{*} \mathrm{P}<0.05$, comparison with the Sham group; one-way ANOVA followed by LSD test. Groups: Treatment, received Nogo-A antibody ( $\mathrm{n}=50)$; Model, received saline ( $\mathrm{n}=50$ ); Sham, Sham-operated rats without cardiac arrest (CA) serving as non-ischemic controls $(n=15)$.

decreased with time. Bcl-2 protein levels were significantly higher in the Treatment group than the Model group at $2 \mathrm{~h}$ $(\mathrm{P}<0.001)$. Hippocampal $\mathrm{Bcl}-2$ protein levels in the Model group were significantly higher than those of the Sham group at $6 \mathrm{~h}$ and significantly lower than those of the Sham group at 2 and $24 \mathrm{~h}(\mathrm{P}<0.05)$. Hippocampal Bcl-2 protein levels in the Treatment group were significantly higher than those of the Sham group at 2 and $6 \mathrm{~h}$ and significantly lower than those of the Sham group at $24 \mathrm{~h}(\mathrm{P}<0.05$; Fig. 8D). 
A

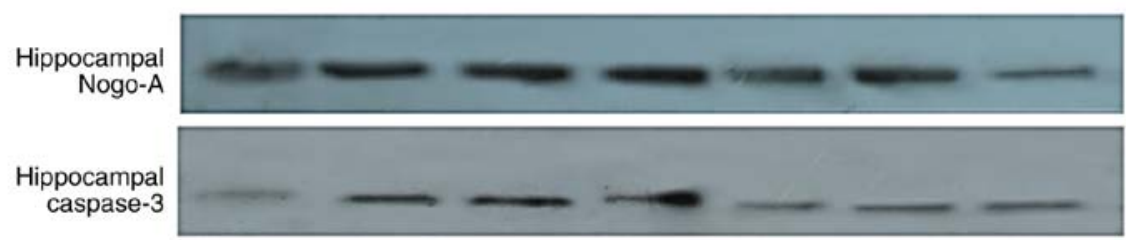

B
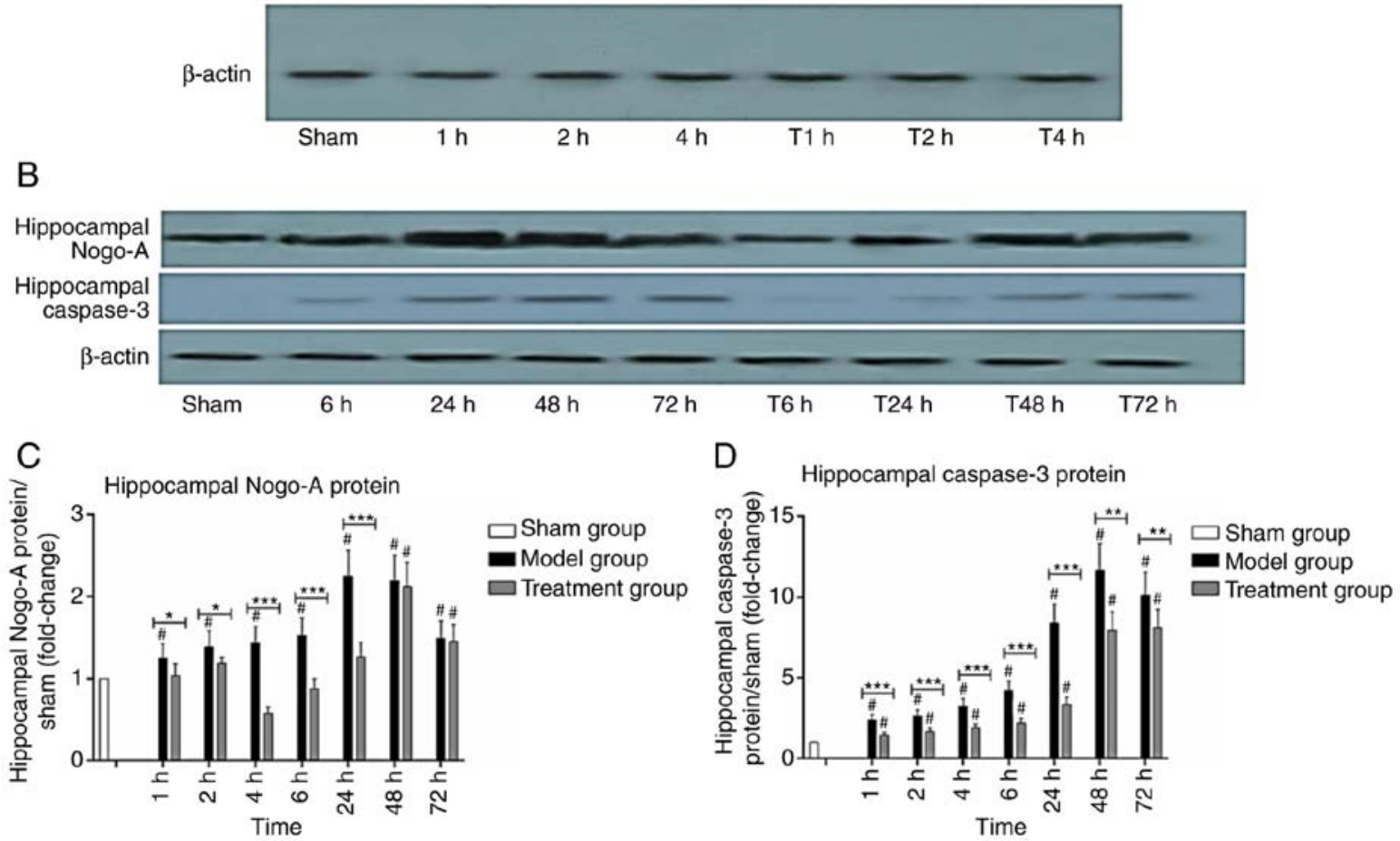

Figure 7. Expression of Nogo-A and caspase-3 protein in the hippocampus (n=3). (A and B) Western blotting for Nogo-A and caspase-3 expression in the hippocampus. (C) Relative levels of Nogo-A. (D) Relative levels of caspase-3, Data are presented as mean \pm SD. Sham group (white), Model group (black), Treatment group (gray). 1, 2, 4, 6, 24, 48 and $72 \mathrm{~h}$ : Model group at 1, 2, 4, 6, 24, 48 and $72 \mathrm{~h}$. T1, T2, T4, T6, T24, T48 and T72 h: Treatment group at 1, 2, 4, 6, 24, 48 and $72 \mathrm{~h} .{ }^{~} \mathrm{P}<0.05,{ }^{* *} \mathrm{P}<0.01$ and ${ }^{* * *} \mathrm{P}<0.001$, comparison between the Model and Treatment group; ${ }^{*} \mathrm{P}<0.05$, comparison with the Sham group; one-way ANOVA followed by LSD test. Groups: Treatment, received Nogo-A antibody ( $\mathrm{n}=50)$; Model, received saline ( $\mathrm{n}=50$ ); Sham, Sham-operated rats without cardiac arrest (CA) serving as non-ischemic controls $(\mathrm{n}=15)$.

Hippocampal Bax protein levels increased gradually with time in the Model group, and decreased after peaking at $6 \mathrm{~h}$. In the Treatment group, they were slightly increased at $2 \mathrm{~h}$, significantly decreased at $4 \mathrm{~h}$, and further increased after $6 \mathrm{~h}$. Hippocampal Bax protein amounts in the Treatment group were significantly lower than those of the Model group at all time-points $(\mathrm{P}<0.05)$. There were differences in Bax protein levels between the Sham group and the Model and Treatment groups $(\mathrm{P}<0.05)$. Hippocampal Bax protein levels in the Model group were significantly higher than those of the Sham group at 2, 4, 6 and $24 \mathrm{~h}(\mathrm{P}<0.05)$. Hippocampal Bax protein levels in the Treatment group were higher than those of the Sham group at 2,6 and $24 \mathrm{~h}$ and lower than those of the Sham group at $4 \mathrm{~h}(\mathrm{P}<0.05$; Fig. 8E).

These findings demonstrated that Nogo-A antibody injection could upregulate GRP78 and Bcl-2 at the protein level, and reduce CHOP, caspase-12 and Bax protein amounts within $24 \mathrm{~h}(\mathrm{P}<0.05)$.

\section{Discussion}

The present study assessed the expression changes in Nogo-A after cardiac arrest/cardiopulmonary resuscitation (CA/CPR) in rats. The results showed that Nogo-A protein levels increased over time in the hippocampus of rats after CA/CPR, consistent with findings by Zhao et al (27) for brain injury and similar with rat studies of ischemia and hypoxia $(5,6,28,29)$. The present study showed that Nogo-A protein levels in the hippocampus were lower in the Treatment group than the Model group, corroborating Weinmann et al (30) and Zhou et al (17). Zhou (17) found that Nogo-A protein levels in brain tissue were significantly reduced by injection with the Nogo-A antibody into the cerebral ventricle of newborn rats with hypoxic ischemic brain injury. He believed that the reason for the decrease in Nogo-A protein was the formation of antigen-antibody complex of Nogo-A. Weinmann et al (30) also found that the total Nogo-A protein amounts in tissues were significantly reduced after Nogo-A antibody injection into the lateral ventricle or subdural cavity of adult rats and rhesus monkeys. Moreover, his study discovered that the internalized Nogo-A and endogenous Nogo-A co-localized in organelles similar to lysosomes or lysosomal progenitors. He also found that antibodies bound to the cell surface and were internalized as antibody ligand complexes. Weinmann et al speculated that the decrease in Nogo-A was due to the reduction of intracellular storage caused by the degradation induced by enhanced antibodies, but whether the synthesis of Nogo-A is also affected still needs to be further studied. 
A

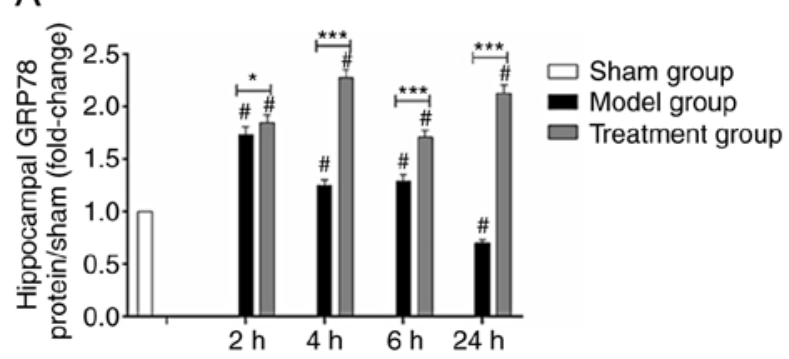

$\mathrm{C}$

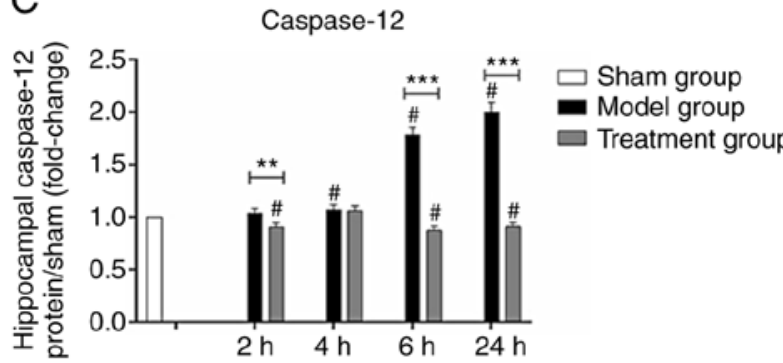

E

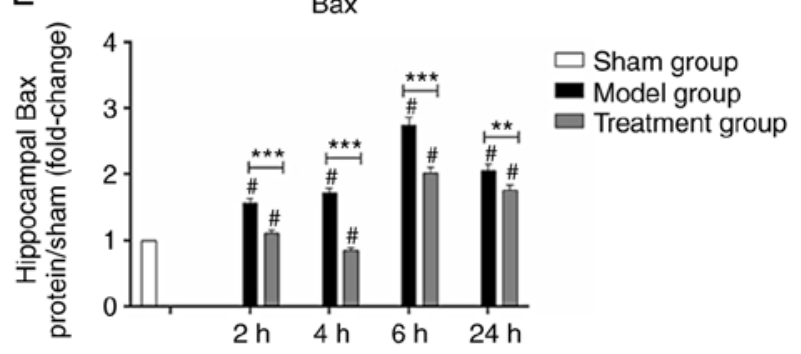

B

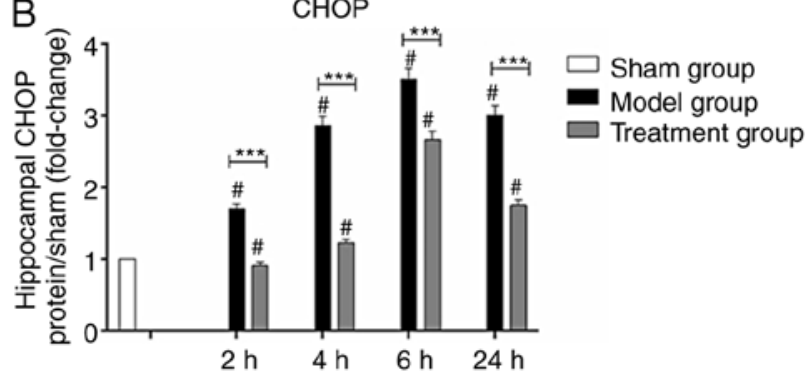

D
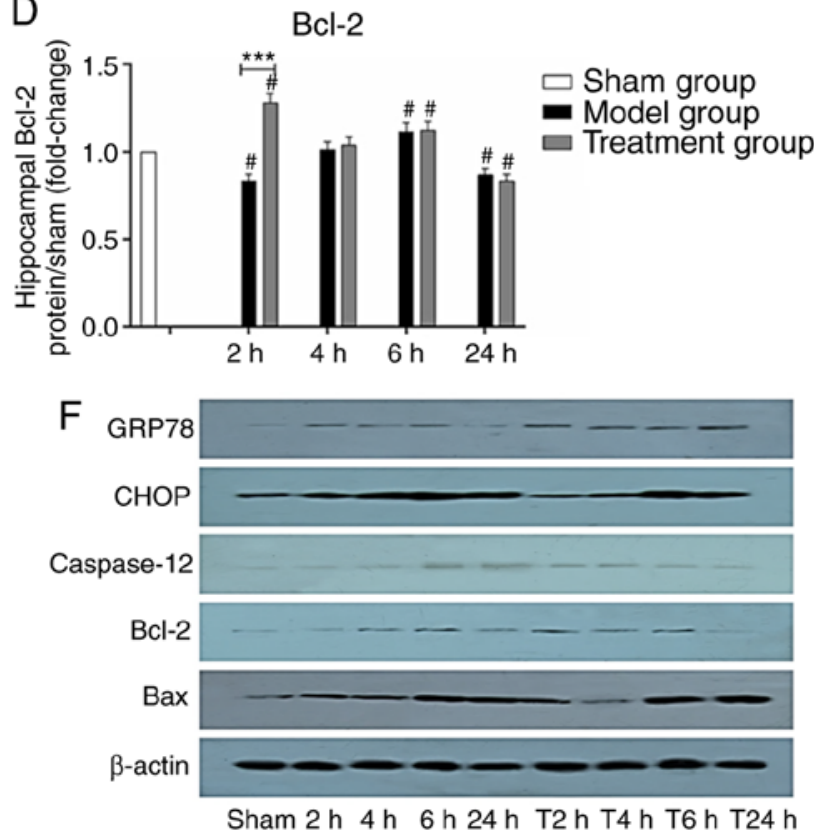

Figure 8. Expression of GRP78, CHOP, caspase-12, Bcl-2 and Bax protein in the hippocampus (n=3). Relative levels of (A) GRP78 expression, (B) CHOP expression, (C) caspase-12 expression, (D) Bcl-2 expression and (E) Bax expression in the hippocampus. (F) Western blotting for GRP78, CHOP, caspase-12, Bcl-2, Bax expression in the hippocampus, GRP78, glucose regulated protein 78; CHOP, C/EBP homologous protein; caspase-12, cysteinyl aspartate specific proteinase-12. Data are presented as mean \pm SD, Sham group (white), Model group (black), Treatment group (gray). 2, 4, 6 and 24 h: Model group at 2, 4, 6 and $24 \mathrm{~h}$. T2, T4, T6 and T24 h: Treatment group at 2, 4, 6 and $24 \mathrm{~h} .{ }^{*} \mathrm{P}<0.05,{ }^{* *} \mathrm{P}<0.01$ and ${ }^{* * *} \mathrm{P}<0.001$, comparison between the Model and Treatment group; ${ }^{\#} \mathrm{P}<0.05$, comparison with the Sham group; one-way ANOVA followed by LSD test. Groups: Treatment, received Nogo-A antibody ( $\mathrm{n}=50$ ); Model, received saline $(n=50)$; Sham, Sham-operated rats without cardiac arrest (CA) serving as non-ischemic controls $(n=15)$.

The present study demonstrated that Nogo-A protein levels were significantly positively correlated with caspase-3 expression in the rat hippocampus $(\mathrm{r}=0.79, \mathrm{P}<0.001)$. Previous studies on ischemic hypoxic brain damage in a newborn SD rat model found that caspase-3 expression was significantly increased along with Nogo-A expression. Application of ephedrine and hyperbaric oxygen treatment could inhibit Nogo-A and caspase-3 expression, alleviating the degree of brain injury caused by ischemia hypoxia (10). Another study assessing the optic nerve also showed increased Nogo-A and caspase-3 amounts after acute injury (31), and found that glucocorticoids reduce Nogo-A and caspase-3 levels. However, the above study failed to assess whether Nogo-A and caspase- 3 are concomitant or causal. The present research revealed that inhibition of Nogo-A expression could reduce caspase- 3 expression, suppressing apoptosis. As shown above, caspase-3 mRNA and protein expression levels, and Nogo-A protein amounts were increased after restoration of spontaneous circulation (ROSC), but decreased after intraventricular injection of the Nogo-A antibody in rats. The expression trend of the Nogo-A protein after intraventricular injection was consistent with that of caspase-3. Specific intervention of Nogo-A expression could reduce caspase-3 expression. Inhibition of Nogo-A expression could downregulate caspase- 3 and inhibit apoptosis. It was also demonstrated that caspase- 3 was associated with Nogo-A, indicating that Nogo-A is involved in the process of apoptosis, which can be reduced by intraventricular injection of Nogo-A antibody. In cultured cardiomyocytes, a study found that knockdown of Nogo-A reduced caspase-3 cleavage and apoptosis in hypoxia/reoxygenation cardiomyocytes (9), corroborating the present findings. Therefore, downregulation of Nogo-A reduces caspase-3 expression, decreases apoptosis and protects neural function.

The present study found that after ROSC, GRP78 levels in the hippocampal tissue were increased compared with those of the Model group, and rapidly increased at $2 \mathrm{~h}$. This is consistent with the GRP78 results for focal ischemic rat brain tissue (32). GRP78, a member of the heat shock protein family, is a classic marker of endoplasmic reticulum (ER) stress and promotes the correct assembly, folding and modification of proteins. Increased expression of GRP78 plays a protective role in cells under stress. After CA/CPR, the brain tissue experiences total 
cerebral ischemia and reperfusion, which causes ER stress and activates the unfolded protein response (UPR) process. When unfolded proteins accumulate in the ER, GRP78 binds to them, dissociating with inositol-requiring enzymel (IRE1), activating transcription factor 6 (ATF6) and double-stranded RNA dependent protein kinase-like ER kinase (PERK), and causing their activation (33). GRP78 activates these three pathways, which regulate GRP78 after activation, and GRP78 subtly modulates the activation of the pathways. Through these mechanisms, GRP78 expression is increased, and the protein binds to misfolded and unfolded proteins in the ER lumen to reduce the ER burden and restore ER function. However, when ER stress is extremely strong, this self-stabilizing effect is weakened, resulting in dysfunctional ER and decreased GRP78 expression (34). This is why GRP78 protein amounts were significantly increased at 4,6 and $24 \mathrm{~h}$ in the Treatment group compared with the Model group, with a delayed peak $(\mathrm{P}<0.01)$ in this study. The peak time of the GRP78 protein in the Treatment group was $4 \mathrm{~h}$, which was consistent with the low ebb time for the Nogo-A protein, and subsequent Nogo-A decrease was consistent with subsequent elevation of GRP78, indicating that reduced Nogo-A protein results in increased expression of the GRP78 protein, alleviates ER stress, and exerts a protective effect on cell survival.

CHOP, also known as growth arrest and DNA-damageinducible gene 153 (GADD153), is also a classical marker of ER stress. Increased expression of CHOP initiates the apoptotic pathway (35). The present study found that CHOP in the hippocampal tissue gradually increased to peak at $6 \mathrm{~h}$ after CA/CPR, and then decreased. CHOP levels were lower in the Treatment group compared with the Model group, and differences between the Model and Treatment groups and Sham group were statistically significant at 2, 4, 6 and $24 \mathrm{~h}$. CHOP is normally widely expressed at a very low level, but highly expressed in cells under stress. After ER stress, the UPR occurs and three pathways are activated. Since CHOP expression (at the gene and protein levels) occurs upon activation of the three pathways of unfolded reactions by GRP78, CHOP can be induced by the above three pathways simultaneously, and its protein expression gradually increases. At the early stage of ER stress, GRP78 is highly expressed and inhibits CHOP expression through the three pathways in order to restore homeostasis. At the later stage, GRP78 expression decreases and CHOP expression is rapidly upregulated. Therefore, the peak of CHOP occurs later than that of GRP78. CHOP is a transcription factor that regulates genes involved in cell survival or death. When cell adaptation through the UPR is unsuccessful due to prolonged or unresolved ER stress, new signals transmitted from the ER induce cell death. UPR's PERK pathway initially mediates the pro-survival response and promotes GRP78 expression; however, in case of severe or prolonged ER stress, a pro-apoptotic response takes place instead (36). CHOP can induce apoptosis in many ways, possibly through inhibition of $\mathrm{Bcl}-2$ transcription. Overexpression of $\mathrm{CHOP}$ leads to decreased $\mathrm{Bcl}-2$ protein levels. In the present study, Bcl-2 levels increased at $2 \mathrm{~h}$ in the Treatment group, which may be related to decreased CHOP protein expression at this time-point. We found that CHOP protein expression levels in the Treatment group were lower at 2, 4, 6 and $24 \mathrm{~h}$ compared with those of the Model group. The CHOP protein decrease in the Treatment group was highest at $4 \mathrm{~h}$, which was consistent with the most obvious decrease in Nogo-A protein levels, indicating that a decrease in Nogo-A protein downregulates $\mathrm{CHOP}$ at the protein level, reduces ER stress, alleviates CHOP protein-induced apoptosis, and has a protective effect on cell survival (37). The present study demonstrated that during CPR, CHOP, GRP78, caspase-12 and Bax in hippocampal tissues were all increased compared with the values of the Sham operation group, Bcl-2 expression was decreased, and the differences were statistically significant. GRP78 peaked at $2 \mathrm{~h}$ and CHOP at $6 \mathrm{~h}$. The variation pattern of $\mathrm{CHOP}$ in our model was similar to previous findings (38). GRP78 and CHOP are both classical markers of ER stress. Increased expression of GRP78 plays a protective role in cells under stress, and increased expression of CHOP is a pathway that initiates apoptosis. Both of them reflect ER stress occurrence.

Caspase-12 is located at the cytoplasmic side of the ER, which hosts caspases. It represents a specific molecule that mediates ER stress and induces apoptosis, and is not activated in the death receptor and mitochondrial pathways, the other two axes of apoptosis (39). Caspase-12 mediates the apoptosis pathway specific to the ER. It directly enters the cytoplasm and activates caspase-9 (3) without relying on the mitochondrial cytochrome C/Apaf-1 pathway, and activates caspase- 3 to induce apoptosis (40).

The present study showed that caspase-12 in the hippocampal tissue was gradually increased after CA/CPR compared with the Sham group, and significantly increased at $6 \mathrm{~h}$, peaking at $24 \mathrm{~h}$, and differences were statistically significant. This is consistent with findings by Osada et al (37). In the latter study, the hippocampal tissue of mice with transient anterior cerebral ischemia was assessed, and caspase-12 was shown to be increased significantly at $24 \mathrm{~h}$. Caspase- 12 also increased in the ischemic core $24 \mathrm{~h}$ after ischemia in the permanent middle cerebral artery occlusion (MCAO) model (41). GRP78, ATF4 and CHOP levels were also shown to be significantly increased in the ischemia reperfusion model of MCAO (38). The increase of ER stress markers was consistent with caspase-12 upregulation in the core area of ischemia at $24 \mathrm{~h}$. In the mouse MCAO model, caspase-12 after 1-h ischemia/reperfusion was found to be associated with GRP78 upregulation and cell apoptosis. CHOP and caspase-12 levels were shown to be increased in the same model at 6-12 $\mathrm{h}$ after reperfusion (42). Meanwhile, caspase-12 expression was increased in the hippocampus of rats with traumatic brain injury, which was found to be associated with neuronal injury. In the present study, the caspase-12 level increased after CA/CPR indicating apoptotic induction by ER stress. As shown above, $\mathrm{CHOP}$ peaked at $6 \mathrm{~h}$ after $\mathrm{CA} / \mathrm{CPR}$, and caspase-12 also increased significantly at that time-point. While CHOP levels decreased in the Treatment group, caspase- 12 amounts did not increase significantly, and no significant peak was observed. Meanwhile, caspase-12 protein expression in the Treatment group was lower than that of the Model group at 2, 6 and $24 \mathrm{~h}$, respectively, with the most significant reductions at 6 and $24 \mathrm{~h}$, and no significant peak formation. We also found that a decrease in Nogo-A protein could inhibit the specific caspase-12 apoptosis pathway induced by ER stress and eventually lead to caspase-3 downregulation, thereby reducing apoptosis.

In addition to its role in the mitochondrial apoptotic pathway, the Bcl-2 protein is also located in the ER and 
reduces the level of calcium ions in a stable state through IP3Rs. The apoptotic protein Bax is also located in the ER and antagonizes the activity of Bcl-2 in regulating the concentration of calcium ions (43). Meanwhile, Bax binds to IRE1 $\alpha$ after ER stress, leading to pathological activation (44), which in turn neutralizes the anti-apoptotic activity of Bcl-2. Bax may play an executor role in ER stress-induced apoptosis. The present study found that there were no significant differences in hippocampal Bcl-2 protein levels between the Treatment and Model groups except at $2 \mathrm{~h}$, which may be associated with the insignificant increase in CHOP protein levels observed at this time-point, as overexpression of CHOP leads to decreased Bcl-2 protein expression. Hippocampal Bax protein levels in the Treatment group were lower than those of the Model group at 2, 4, 6 and $24 \mathrm{~h}$, respectively, since CHOP overexpression leads to increased Bax expression. The expression of $\mathrm{CHOP}$ was inhibited in the Treatment group, thus Bax expression was decreased.

The limitations of this research should be mentioned. Firstly, the observation time after ROSC was relatively short (72 h), and further studies should prolong the observation period to at least 1 to 3 months after ROSC to observe long-term effects. Secondly, a single drug dose was assessed; optimal timing and dosage should be comprehensively tested in further investigation. Thirdly, only hippocampal injury was evaluated after ROSC, and it remains unclear whether other parts of the brain such as the corpus striatum were equally affected. Fourthly, this study adopted a bolus injection for $20 \mathrm{~min}$. We found that the effects would not exceed $24 \mathrm{~h}$, thus further studies should deliver antibodies over several days or weeks to maintain the drug effects for a longer time. Meanwhile, further studies are required in posttreatment settings.

In conclusion, the present study found that after intracerebroventricular injection of Nogo-A antibody to rats after ROSC, cell apoptosis was reduced, the morphological structure and ultrastructure were preserved, and neurological function was improved. These results suggest that the Nogo-A antibody has certain protective effects on brain structure and function in rats after ROSC. The protective mechanism possibly includes GRP78 and Bcl-2 upregulation, and CHOP, Bax and caspase-12 downregulation, ER stress inhibition, and finally suppression of caspase-3-associated apoptosis. The anti-Nogo-A antibody could protect brain structure and function in rats after ROSC by reducing ER stress-induced apoptosis.

\section{Acknowledgements}

Not applicable.

\section{Funding}

This study was supported by the Sichuan Science and Technology Program (grant nos. 2013SZ0079 and 2017RZ0046) and the Youth Teacher Research Startup Fund of Sichuan University (grant no. 2016SCU11016).

\section{Availability of data and materials}

The datasets used and/or analyzed during the current study are available from the corresponding author on reasonable request.

\section{Authors' contributions}

All authors designed the experiments. QW and HZ carried out the experiments and associated data analysis. QW drafted the manuscript. ZZ and HN interpreted the data and revised the manuscript. All authors read and approved the final version of the manuscript.

\section{Ethics approval and consent to participate}

The West China Hospital's Experimental Animal Ethics Committee approved the study protocol.

\section{Patient consent for publication}

Not applicable.

\section{Competing interests}

The authors declare that they have no competing interests.

\section{References}

1. Madder RD and Reynolds JC: Multidisciplinary management of the post-cardiac arrest patient. Cardiol Clin 36: 85-101, 2018.

2. Neumar RW, Nolan JP, Adrie C, Aibiki M, Berg RA, Böttiger BW Callaway C, Clark RS, Geocadin RG, Jauch EC, et al: Post-cardiac arrest syndrome: Epidemiology, pathophysiology, treatment, and prognostication. A consensus statement from the International Liaison Committee on Resuscitation (American Heart Association, Australian and New Zealand Council on Resuscitation, European Resuscitation Council, Heart and Stroke Foundation of Canada, InterAmerican Heart Foundation, Resuscitation Council of Asia, and the Resuscitation Council of Southern Africa); the American Heart Association Emergency Cardiovascular Care Committee; the Council on Cardiovascular Surgery and Anesthesia; the Council on Cardiopulmonary, Perioperative, and Critical Care; the Council on Clinical Cardiology; and the Stroke Council. Circulation 118: 2452-2483, 2008.

3. Taccone FS, Crippa IA, Dell'Anna AM and Scolletta S: Neuroprotective strategies and neuroprognostication after cardiac arrest. Best Pract Res Clin Anaesthesiol 29: 451-464, 2015.

4. Cherry BH, Sumien N and Mallet RT: Neuronal injury from cardiac arrest: Aging years in minutes. Age (Dordr) 36: 9680, 2014.

5. Wang $\mathrm{H}$, Yao Y, Jiang $\mathrm{X}$, Chen $\mathrm{D}$, Xiong $\mathrm{Y}$ and $\mathrm{Mu} \mathrm{D}$ : Expression of Nogo-A and $\mathrm{NgR}$ in the developing rat brain after hypoxia-ischemia. Brain Res 1114: 212-220, 2006.

6. Zhou CM, Li Y, Nanda A and Zhang JH: HBO suppresses Nogo-A, Ng-R, or RhoA expression in the cerebral cortex after global ischemia. Biochem Biophys Res Commun 309: 368-376, 2003.

7. Ulndreaj A, Badner A and Fehlings MG: Promising neuroprotective strategies for traumatic spinal cord injury with a focus on the differential effects among anatomical levels of injury. F1000Res 6: 1907, 2017.

8. Zhang ZW, Jiang JJ, Luan MC, Ma ZJ, Gao F and Yu SJ: Nogo-A antibody treatment enhances neuron recovery after sciatic nerve transection in rats. Eur Rev Med Pharmacol Sci 21: 1780-1786, 2017.

9. Sarkey JP, Chu M, McShane M, Bovo E, Ait Mou Y, Zima AV, de Tombe PP, Kartje GL and Martin JL: Nogo-A knockdown inhibits hypoxia/reoxygenation-induced activation of mitochondrial-dependent apoptosis in cardiomyocytes. J Mol Cell Cardiol 50: 1044-1055, 2011.

10. Chen S, Xiao N and Zhang X: Effect of combined therapy with ephedrine and hyperbaric oxygen on neonatal hypoxic-ischemic brain injury. Neurosci Lett 465: 171-176, 2009.

11. Chen S, Novick P and Ferro-Novick S: ER structure and function. Curr Opin Cell Biol 25: 428-433, 2013. 
12. Rämö O, Kumar D, Gucciardo E, Joensuu M, Saarekas M Vihinen H, Belevich I, Smolander OP, Qian K, Auvinen P and Jokitalo E: NOGO-A/RTN4A and NOGO-B/RTN4B are simultaneously expressed in epithelial, fibroblast and neuronal cells and maintain ER morphology. Sci Rep 6: 35969, 2016.

13. Liu D, Zhang M and Yin H: Signaling pathways involved in endoplasmic reticulum stress-induced neuronal apoptosis. Int J Neurosci 123: 155-162, 2013

14. Idris AH, Becker LB, Ornato JP, Hedges JR, Bircher NG, Chandra NC, Cummins RO, Dick W, Ebmeyer U, Halperin HR, et al: Utstein-style guidelines for uniform reporting of laboratory CPR research. A statement for healthcare professionals from a task force of the American Heart Association, the American College of Emergency Physicians, the American College of Cardiology, the European Resuscitation Council, the Heart and Stroke Foundation of Canada, the Institute of Critical Care Medicine, the Safar Center for Resuscitation Research, and the Society for Academic Emergency Medicine. Writing Group. Circulation 94: 2324-2336, 1996.

15. Chen MH, Liu TW, Xie L, Song FQ, He T, Zeng ZY and Mo SR Ventricular fibrillation induced by transoesophageal cardiac pacing: A new model of cardiac arrest in rats. Resuscitation 74: 546-551, 2007

16. Labak M, Foniok T, Kirk D, Rushforth D, Tomanek B, Jasiński A and Grieb P: Metabolic changes in rat brain following intracerebroventricular injections of streptozotocin: A model of sporadic Alzheimer's disease. Acta Neurochir Suppl 106: 177-181, 2010.

17. Zhou XG, Liu RH and Xiong AH: Effect of ventricle injection of Nogo-A antibody on neuronal regeneration following hypoxic-ischemic brain damage in the neonatal rat. Zhongguo Dang Dai Er Ke Za Zhi 9: 301-304, 2007 (In Chinese).

18. Ineichen BV, Schnell L, Gullo M, Kaiser J, Schneider MP, Mosberger AC, Good N, Linnebank M and Schwab ME: Direct, long-term intrathecal application of therapeutics to the rodent CNS. Nat Protoc 12: 104-131, 2017.

19. Geocadin RG, Ghodadra R, Kimura T, Lei H, Sherman DL, Hanley DF and Thakor NV: A novel quantitative EEG injury measure of global cerebral ischemia. Clin Neurophysiol 111: $1779-1787,2000$

20. Ye S, Weng Y, Sun S, Chen W, Wu X, Li Z, Weil MH and Tang W: Comparison of the durations of mild therapeutic hypothermia on outcome after cardiopulmonary resuscitation in the rat. Circulation 125: 123-129, 2012.

21. Birnie M, Morrison R, Camara R and Strauss KI: Temporal changes of cytochrome P450 (Cyp) and eicosanoid-related gene expression in the rat brain after traumatic brain injury. BMC Genomics 14: 303, 2013.

22. Livak KJ and Schmittgen TD: Analysis of relative gene expression data using real-time quantitative PCR and the 2(-Delta Delta C(T)) method. Methods 25: 402-408, 2001.

23. Mavridis K, Stravodimos K and Scorilas A: Downregulation and prognostic performance of microRNA 224 expression in prostate cancer. Clin Chem 59: 261-269, 2013.

24. Eslamizade MJ, Madjd Z, Rasoolijazi H, Saffarzadeh F, Pirhajati $\mathrm{V}$, Aligholi $\mathrm{H}$, Janahmadi $\mathrm{M}$ and Mehdizadeh $\mathrm{M}$ : Impaired memory and evidence of histopathology in CA1 pyramidal neurons through injection of $\mathrm{A} \beta 1-42$ peptides into the frontal cortices of rat. Basic Clin Neurosci 7: 31-41, 2016.

25. Zhao BB, Long QH, Wang CY, Chen LL, Xie GJ, Bo WJ, Xu B, $\mathrm{Li} \mathrm{ZF,} \mathrm{Li} \mathrm{HM} \mathrm{and} \mathrm{Wang} \mathrm{P:} \mathrm{Protective} \mathrm{effects} \mathrm{of} \mathrm{Liu} \mathrm{Wei} \mathrm{Di}$ Huang Wan on the liver, orbitofrontal cortex nissl bodies, and neurites in MSG+PH-induced liver regeneration rat model. Evid Based Complement Alternat Med 2018: 9090128, 2018.

26. França MS, Moron AF, Araujo Júnior E, Avedissian M, Pares DB, Nardozza LM, Jaqueta CB and Mello LE: Neonatal neuronal apoptosis after betamethasone administration in pregnant Wistar rats. J Matern Fetal Neonatal Med 29: 1089-1093, 2016.

27. Zhao X, Song JN, Xi L, Sui L, Wang WB and Liu XB: Expression changes of Nogo-A and its significance in rat brain with diffusive axonal injury. J Xi'an Jiaotong Univ (Medical Sciences) 36 $80-84,2015$.
28. Marklund N, Fulp CT, Shimizu S, Puri R, McMillan A Strittmatter SM and McIntosh TK: Selective temporal and regional alterations of Nogo-A and small proline-rich repeat protein 1A (SPRR1A) but not Nogo-66 receptor $(\mathrm{NgR})$ occur following traumatic brain injury in the rat. Exp Neurol 197: 70-83, 2006.

29. Jiang W, Xia F, Han J and Wang J: Patterns of Nogo-A, NgR, and RhoA expression in the brain tissues of rats with focal cerebral infarction. Transl Res 154: 40-48, 2009.

30. Weinmann O, Schnell L, Ghosh A, Montani L, Wiessner C, Wannier T, Rouiller E, Mir A and Schwab ME: Intrathecally infused antibodies against Nogo-A penetrate the CNS and downregulate the endogenous neurite growth inhibitor Nogo-A. Mol Cell Neurosci 32: 161-173, 2006.

31. Yu J, Lin L, Luan X, Jing C and Maierab: Impacts of Rho kinase inhibitor Fasudil on Rho/ROCK signaling pathway in rabbits with optic nerve injury. Int J Clin Exp Pathol 8: 14717-14724, 2015.

32. Aoki M, Tamatani M, Taniguchi M, Yamaguchi A, Bando Y Kasai K, Miyoshi Y, Nakamura Y, Vitek MP, Tohyama M, et al: Hypothermic treatment restores glucose regulated protein 78 (GRP78) expression in ischemic brain. Brain Res Mol Brain Res 95: 117-128, 2001.

33. Wang S and Kaufman RJ: The impact of the unfolded protein response on human disease. J Cell Biol 197: 857-867, 2012.

34. Xiaoyan S, Zhao YB, Zhou XL, Wu YC and Liu WW: Changes in the expression of endoplasmic reticulum stress-related factors after cerebral ischemia reperfusion in rats. Chin J Nerv Ment Dis 33: 624-626, 2007.

35. Zhao J, Xiang X, Zhang H, Jiang D, Liang Y, Qing W, Liu L, Zhao Q and He Z: CHOP induces apoptosis by affecting brain iron metabolism in rats with subarachnoid hemorrhage. Exp Neurol 302: 22-33, 2018.

36. Gardner BM, Pincus D, Gotthardt K, Gallagher CM and Walter P: Endoplasmic reticulum stress sensing in the unfolded protein response. Cold Spring Harb Perspect Biol 5: a013169, 2013.

37. Osada N, Kosuge Y, Ishige K and Ito Y: Characterization of neuronal and astroglial responses to ER stress in the hippocampal CA1 area in mice following transient forebrain ischemia. Neurochem Int 57: 1-7, 2010.

38. Nakka VP, Gusain A and Raghubir R: Endoplasmic reticulum stress plays critical role in brain damage after cerebral ischemia/ reperfusion in rats. Neurotox Res 17: 189-202, 2010.

39. Nan L, Yan L and Niu ZH: Effects of ischemic postconditioning on endoplasmic reticulum stress pathways in rats with cerebral ischemia/reperfusion injury. J Stroke Neurol Dis 31: 203-206, 2014.

40. Weston RT and Puthalakath H: Endoplasmic reticulum stress and BCL-2 family members. Adv Exp Med Biol 687: 65-77, 2010.

41. Mouw G, Zechel JL, Gamboa J, Lust WD, Selman WR and Ratcheson RA: Activation of caspase-12, an endoplasmic reticulum resident caspase, after permanent focal ischemia in rat. Neuroreport 14: 183-186, 2003.

42. Zhu H, Zhu H, Xiao S, Sun H, Xie $\mathrm{C}$ and Ma Y: Activation and crosstalk between the endoplasmic reticulum road and JNK pathway in ischemia-reperfusion brain injury. Acta Neurochir (Wien) 154: 1197-1203, 2012.

43. Byrd AE, Aragon IV and Brewer JW: MicroRNA-30c-2* limits expression of proadaptive factor XBP1 in the unfolded protein response. J Cell Biol 196: 689-698, 2012.

44. Hetz C, Bernasconi P, Fisher J, Lee AH, Bassik MC, Antonsson B, Brandt GS, Iwakoshi NN, Schinzel A, Glimcher LH and Korsmeyer SJ: Proapoptotic BAX and BAK modulate the unfolded protein response by a direct interaction with IRE1alpha. Science 312: 572-576, 2006.

This work is licensed under a Creative Commons Attribution-NonCommercial-NoDerivatives 4.0 International (CC BY-NC-ND 4.0) License. 